\title{
Final Report on Funding
} for the

University of Florida Training Reactor Through the U.S. Department of Energy University Reactor Instrumentation Program

\section{Grant No. DE-FG07-90ER12969}

FINAL REPORT

FOR 1990-1992

Dr. William G. Vernetson

Director of Nuclear Facilities

\section{NUCLEAR REACTOR FACILITY NUCLEAR ENGINEERING SCIENCES DEPARTMENT UNIVERSITY OF FLORIDA}

GAINESVILLE,FLORIDA

November, 1992 


\section{TABLE OF CONTENTS}

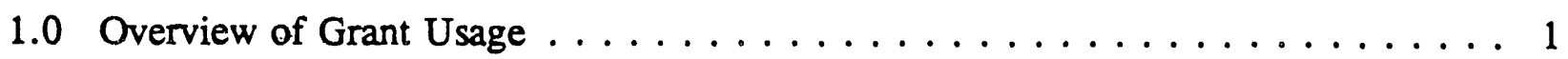

2.0 Review of First Year Grant Usage $\ldots \ldots \ldots \ldots \ldots \ldots$

3.0 Summary of Second Year Grant Usage . . . . . . . . . . . . . . . . . . . . 4

4.0 Final Grant Summary $\ldots \ldots \ldots \ldots \ldots$

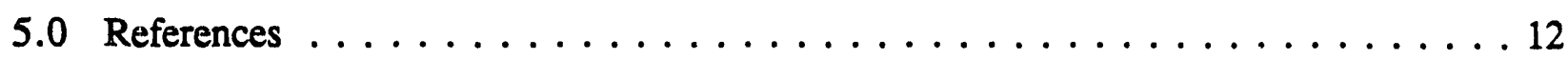

\section{TABLES}

Table 1 Total Cost For Proposed UFTR Facility Instrumentation and Equipment Upgrade for 1990-1991 Grant Year . . . . . . . . . . . 13

Table 2 Financial Results of UFTR 1990-1991 University Reactor Instrumentation Grant . . . . . . . . . . . . . . . 15

Table 3 Total Cost For Proposed UFTR Facility Instrumentation and Equipment Upgrade For 1991-1992 Grant Year . . . . . . . . . . . . . 16

Table 4 Financial Results of UFTR 1991-1992 University Reactor Instrumentation Grant . . . . . . . . . . . . . . . 17

\section{DISCLAIMER}

This report was prepared as an account of work sponsored by an agency of the United States Government. Neither the United States Government nor any agency thereof, nor any of their employees, makes any warranty, express or implied, or assumes any legal liability or responsibility for the accuracy, completeness, or usefulness of any information, apparatus, product, or process disclosed, or represents that its use would not infringe privately owned rights. Reference herein to any specific commercial product, process, or service by trade name, trademark, manufacturer, or otherwise does not necessarily constitute or imply its endorsement, recommendation, or favoring by the United States Government or any agency thereof. The views and opinions of authurs expressed herein do not necessarily state or reflect those of the United States Government or any agency thereof. 
Final Report on 1990-1992

University Reactor Instrumentation Grant

\subsection{Overview of Grant Usage}

Recognizing that the University Reactor Instrumentation Program was developed in response to widespread needs in the academic community for modernization and improvement of research and training reactors at institutions such as the University of Florida, the items proposed to be supported by this grant over its two year period have been selected as those most likely to reduce forced outages, to meet regulatory concerns that had been expressed in recent years by Nuclear Regulatory Commission inspectors or to correct other facility problems and limitations. Department of Energy Grant Number DE-FG07-90ER129969 was provided to the University of Florida Training Reactor(UFTR) facility through the U.S. Department of Energy's University Reactor Instrumentation Program. The original proposal submitted in February, 1990 requested support for UFTR facility instrumentation and equipment upgrades for seven(7) items in the amount of $\$ 107,530$ with $\$ 13,800$ of this amount to be the subject of cost sharing by the University of Florida and $\$ 93,730$ requested as support from the Depariment of Energy. A breakdown of the items requested and total cost for the proposed UFTR facility instrumentation and equipment improvements is contained in Table 1 taken from the proposal submittal.

The three items actually supported by the grant allocation in the first year provided a starting point for the process of modernization and improvement at the University of Florida Training Reactor which, like the majority of such facilities, is over 30 years old. Although several major instrumentation improvements were supported by the University of Flerida around 
1970 and later, it had been some years since significant funding had been available for reactor facility instrumentation upgrades. By no means did this grant meet all the clearly identified needs of a facility such as the UFTR, but it did allow the process to continue. For more details on the grant usage for the first year, the reader is referred to Section 2.0 and to Reference 1.

For the second grant year, the original proposal submitted in February, 1991 requested support for UFTR facility instrumentation and equipment upgrades for ten(10) items in the amount of $\$ 108,948$ with $\$ 16,900$ of this amount to be the subject of cost sharing by the University of Florida and $\$ 92,048$ requested as support from the Department of Energy. Again these items were directed at improving reactor facility operation and addressing facility shortcomings identified by internal reviews related to forced outages and other limitations as well as concerns expressed by regional NRC inspectors. In the second grant year we have again acquired and implemented badly needed instrumentation for the facility. Again, it meets some clearly identified needs but by no means does it mean even a significant fraction of all the identified needs of the facility have been met. The six items that have been acquired under the grant in the second year do assure that some key needs have been addressed.

\subsection{Review of First Year Grant Usage}

Although only a portion of the proposal could be funded, a number of key items were included in the first year grant referenced previously. Specifically, this first DOE reactor instrumentation grant was awarded for $\$ 25,700$ subject to an additional $12.83 \%$ cost sharing per the original proposal, to provide funds toward the purchase of the following much needed instrumentation: 


\section{Air Particulate Detector System}

2. Two-Pen Recorder for the Reactor Console

\section{Single Unit Safety Channel.}

The quoted estimated costs from the February, 1990 proposal and actual costs for the items covered under this grant are summarized in Table 2; in addition, total actual cost shown in Column 2 is $\$ 3,557.76$ less than was projected in the proposal with two items costing somewhat more than proposed and the two-pen recorder costing considerably less. This savings means that the grant was charged as shown in Column 4 with cost sharing shown in Column 5 of Table 2. It had been hoped that the unused portion of the grant at $\$ 3,347.66$ might eventually be able to be used for other items, especially since the funding supplied by the grant was well used in getting quality equipment at the best price possible.

As indicated in Table 2, the air particulate detector system cost somewhat more than quoted in the proposal. This instrument is a high quality, air particulate detector or continuous air monitor. Replacement of this piece of instrumentation was high on the list of UFTR priorities for instrumentation replacement. The AMS-3A has given trouble-free operation since installation and has been running simultaneously with the previously installed but outdated air particulate detector system for baseline data tracking purposes.

Second, the two-pen recorder system for the reactor console cost considerably less than quoted in the proposal because the recorder was obtained from a new manufacturer which did not exist at the time of the original proposal submittal in February, 1990. This two-pen recorder was a priority for replacement under the University Reactor Instrumentation Grant. Based on previous years of forced unavailability, it is estimated that this recorder obtained through funding 
support from the University Reactor Instrumentation Grant has prevented at least 60 days forced unavailability in the latest two reporting years ending August 31, 1992 and continues to give trouble-free service.

Finally, the Single Unit Safety Channel was obtained at a somewhat higher cost than proposed(See Table 2). It was included as a priority in the proposed instrumentation because of a possible need to replace a potentially failing Safety Channel 1 in the UFTR console which had experienced two momentary failures in previous years. The Single Unit Safety Channel is a new General Atomics design; therefore, it must receive a full 10 CFR 50.59 safety review and evaluation prior to installation. This safety review and evaluation is still in progress with the instrument modified and expected soon to be approved for installation when needed as indicated in the original proposal.

In general, all three pieces of instrumentation acquired in the first year are directly related to improving reactor safety and addressing inspection concerns in recent years. With these acquisitions forced outage time from several recurring failures was significantly reduced. The result has been improved, more reliable reactor utilization in keeping with grant objectives; this has also meant increased user interest in facility utilization.

\subsection{Summary of Second Year Grant Usage}

For the record reporting year, Department of Energy Grant Number DE-FG0790ER 13969 was again provided to the University of Florida Training Reactor(UFTR) facility through the U.S. Department of Energy's University Reactor Instrumentation Program. The original proposal submitted in February, 1991 requested support for UFTR facility 
instrumentation and equipment upgrades for ten(10) items in the amount of $\$ 108,948$ with $15.51 \%$ cost sharing by the University of Florida. A breakdown of the items requested and total cost for the proposed UFTR facility instrumentation and equipment improvements is contained in Table 3 taken from the proposal submittal. It should be noted that the proposed UFTR facility instrumentation and equipment is subdivided into three categories (I) to improve reactor operations, (II) to improve existing facility/NAA laboratory operations and finally(III) to expand facility capability. All of these items were selected recognizing the objectives of the University Reactor Instrumentation Program to respond to the widespread needs in the academic community for modernization and improvement of research and training reactor facilities, especially at large and diverse institutions such as the University of Florida. These needs are particularly pressing at the UFTR which is the only such research and training reactor in the State of Florida which is undergoing rapid growth in a variety of technical areas.

The six items actually supported by the grant allocation all come from Category I or Category II of the proposal; as in the first grant year, they assure continuation of the process of modernization and improvement at the University of Florida Training Reactor. In future years, we would hope to make even greater progress in modemizing and improving reactor facility instrumentation, hopefully to include acquisition of some instrumentation in Category III to expand facility capabilities to meet expressed needs of the user community served by the University of Florida Training Reactor.

Although only a portion of the proposal could be funded, a number of key items were included in the second year of the grant referenced previously. Specifically, this second DOE grant was awarded for $\$ 22,070$ subject to an additional $15.51 \%$ cost sharing per the original 
proposal submitted in February, 1991, to provide funds toward the purchase of the following much needed instrumentation:

1. Dual Channel High Speed Chart Recorder

2. Portable Neutron Sensitive Monitor

3. Electronic Maintenance Tool Kit Package

4. External Multichannel Buffer

5. Spectrum Master

6. Low Background Lead shield

The quoted estimated costs from the February, 1991 proposal and actual costs as well as status for the items covered under this grant are summarized in Table 4; in addition, total actual cost shown in Column 2 is $\$ 487.61$ more than was projected in the proposal with three items costing somewhat more than proposed and two costing somewhat less with the low background lead shie!d unchanged. This means that the grant was charged as shown in Column 4 with cost sharing shown in Column 5 of Table 2. It is hoped that the unused portion of the previous 1990-1991 instrumentation grant at $\$ 3,347.66$ may eventually be able to be used to cover the $\$ 487.61$ excess on this year's grant or even to cover other items, especially since the funding supplied by the earlier first year grant was well used in getting quality equipment at the best price possible.

First, as indicated in Table 4, the dual channel portable high speed chart recorder to perform post-trip and periodic surveillance timing checks on the reactor control blade drive system cost somewhat less than quoted in the proposal. The previously used in-house recorder had been the object of literally many dozens of maintenance actions until it finally failed beyond 
repair about 2-1/2 years ago. Lack of an in-house recorder to perform post-trip and regularly scheduled control blade drop time checks had resulted in many days unavailability over a two year period. One can usually be borrowed but the delay involved had caused considerable problems in availability, especially with unplanned post-trip checks. The new instrument acquired under the Reactor Instrumentation Grant is a high quality, state-of-the-art recorder whose final acquisition was delayed until near the end of the grant year as it required a minor modification for full implementation in the UFTR Technical Specifications-mandated surveillance program. The recorder is now available for use in timing control blade drop times and should contribute substantially to improved reactor utilization through elimination of outage time following trips and through response to NRC inspector comments on lack of an in-house, readily available recorder.

Second, the portable neutron sensitive survey meter to replace the one previously in use (on loan) but extremely unreliable cost considerably less than quoted in the proposal. The instrument previously in use and now serving as a spare is approximately 16 years old and is a significant source of reactor unavailability with maintenance performed on it repeatedly in the previous two reporting years, several times causing postponement of planned operations in radiography or planned environmental surveillances resulting essentially in reactor unavailability until the meter could be repaired or a workable replacement could be obtained on loan (not usually possible).

The third item per Table 4 is not a single item but an electronics maintenance tool kit package to facilitate in-house console and process instrumentation repairs; its cost was somewhat above that listed in the proposal. Lack of a complete, well-stocked electronics maintenance tool 
kit package had hampered repairs, troubleshooting and even some planned and unplanned surveillances such as nuclear instrumentation calibrations or required post-trip electronics checkouts. With a relatively complete package available in-house for most of the year, optimal usage of operations personnel has been greatly facilitated and the length of outages involving electrical/electronic failures has been significantly reduced. It is estimated that this kit alone has saved over three weeks of unavailability in the nine months since it was implemented.

The fourth item acquired per Table 4 is an external multichannel buffer(MCB) to improve performance in the real-time data acquisition in one of the two PC-based analyzer systems in the analytical laboratory at a somewhat higher cost than quoted in the proposal. This state-of-the-art design technique for the analog-to-digital converter allows $16 \mathrm{~K}$ channels for data memory and over 2 billion coursts per channel. Coupled with the computer interface board, this new MCB now allows 4 times more data memory then the previous system. Analysis is also now possible for several isotopes emitting low-energy gammas. The external MCB also allows a 50\% increase in data processing of throughput. High-intensity samples now require only half the time previously allotted to achieve the desired sensitivity(counts per channel) which has had the expected benefit of allowing significantly increased laboratory sample throughput. As a result more reactor usage can be accommodated to support actuation analysis with better results obtained to serve facility users both within the University of Florida community and in the broader educational/research community around the State of Florida and beyond.

The fifth item acquired per Table 4 is a spectrum master with several NIM modules in one package with high performance functions and special features available for handling the primary objective of the analytical laboratory which is spectroscopic analysis of neutron-activated samples 
for trace element identification. The cost of this package was slightly more than quoted in the proposal. Important features of spectrum master include computer-controlled gain, fine gain, shaping time and an automatic pole-zero adjustment circuit (eliminating the use of an oscilloscope). Pulse shaping is by a state-of-the-art triangular gilter method with special dead time correction. The computer control of all major functions allows one spectroscopy system to be used with minimal technical background and supervision. Another improvement with the addition of the spectrum master to the present NAA system is a digital spectrum stabilizer which provides better spectral stability over long counting periods, wide ranges of count-rate and temperature variations. A further improvement to the NAA facility is the sample changer port on the spectrum master. Overall, these features increase allowed throughput by close to an order of magnitude as fully implemented during this past year, again facilitating increased reactor usage and service to users which can only encourage and support further growth in facility utilization at all levels.

Finally, the sixth item is an integral, low background lead shield whose cost was the same as in the proposal. The previous shielding configuration on one system was especially poor and limited research grade performance due to high background radiation. It also made certain environmental sample evaluations required by technical specifications very difficult. Implementation of the low-background lead shield with a copper liner to reduce the interference from lead $x$-rays has significantly improved HPGe detector performance. The benefits include reduced counting time and lower detection limits. The new lead shield also accommodates a properly-sized Marinelli beaker to permit the counting and analysis of air samples in a lowbackground environment to respond to previous NRC inspector comments about the UFTR 
environmental surveillance program for gaseous effluents. Again this acquisition not only improves the quality of laboratory output, but it is directly responsive to stated to stated inspector concerns for quality radioactive release measurements and to continued improvement in the overall quality of laboratory analytical output for facility users.

\subsection{Final Grant Summary}

Overall, the instrumentation obtained under the first 1990-1991 University Reactor Instrumentation Program assured that the goals of the Program were well understood and met as well as possible at the level of sur on provided for the University of Florida Training Reactor facility. Though the initial grant support of $\$ 25,700$ provided toward the purchase of $\$ 29,200$ of proposed instrumentation certainly did not meet all of the facility's needs, the instrumentation items obtained and implemented did meet some critical needs and hence the goals of the Program to support modemization and improvement of reactor facilities such as the UFTR within the academic community. Similarly, the instrumentation obtained under the second 1991-1992 University Reactor Instrumentation Program grant has again met some of the critical needs for instrumentation support at the UFTR facility. Again, though the grant support of $\$ 22,070$ provided toward $\$ 26,118$ of proposed instrumentation does not need all of the facility's needs, it does assure continued facility viability and improvement in operations.

Certainly, reduction of forced unavailability of the reactor is the most obvious achievement of the University Reactor Instrumentation Grant program to date at the UFTR. Nevertheless, the ability to close out several expressed inspection concerns of the Nuclear Regulatory Commission with acquisition of the air particulate detector system, the low background lead 
shield and other items is also very important. Most importantly, with modest cost sharing the facility has been able to continue and even accelerate the improvement and modernization of a facility that is used by nearly every post-secondary school in the state of Florida, and several in other states, by dozens of departments within the University of Florida and by several dozen high schools around the state of Florida on a regular basis. Better, more reliabie service to such a broad based user community can only support further growth in quality facility usage.

In the past year this instrumentation grant has supported instrumentation and equipment upgrades not only to improve reactor operations but also to improve existing facility/NAA Laboratory operations to support and facilitate reactor utilization. Indeed, one of the significant amitations in usage of the UFTR facility has been the throughput of the NAA Laboratory(NAAL). The fewer personnel and less equipment time used in the NAAL, the more usage of the reactor that can be accommodated and the more users that can be accommodated in the NAA Laboratory facility. A number of NAAL improvements have been implemented with facility and University of Florida support including upgrading primary and support software packages for spectral analysis; nevertheless, in addition to the software, several additional improvements in the UFTR facility's existing NAA Laboratory capabilities were badly needed to increase productivity to suppnrt further expansion of usage, particularly among those intending to learn to use the laboratory facilities themselves. Acquisition of these items this year through the Instrumentation Grant has significantly increased and improved throughput of the laboratory facility through decreased analysis time and/or personnel time commitments in the analysis facility. The result is more and higher quality reactor operations as well as improved and more reliable results for NAA Laboratory results including several surveillances required by UFTR 
Technical Specifications.

As newer, more reliable state-of-the-art instrumentation is implemented at the UFTR facility, the message from the Department of Energy to the broad based diverse community of users is that the mission of university reactors such as the University of Florida Training Reactor is regarded as important and should be supported. Since the technically trained and educated cadre produced by facilities such as the UFTR is needed throughout the nuclear energy Justry wherever radiation or radioactivity is used, this message is most important for the technological future of this country. It is sincerely hoped that this University Reactor Instrumentation Program can be continued and is level of funding increased in future years to meet the program's stated objective of improving and modernizing operation of university reactors to an even higher degree.

\subsection{References}

a. W.G. Vernetson, "Final Report on Funding for the University of Florida Training Reactor through the U.S. Department of Energy University Reactor Instrumentation Program" Grant No. DE-FG07-90ER 12969, Final Report Submitted To DOE For 1990-1991 Grant Year, April, 1992. 
Table 1

\section{TOTAL COST FOR PROPOSED UFTR FACILITY INSTRIUMENTATION AND EQUIPMENT UPGRADE FOR 1990-1991 GRANT YEAR}

I. Instrumentation/Equipment to Improve UFTR Operations

1. Air Particulate Deter tor System

$\$ \quad 4,000$

2. Two-Pen Recorder

3. Single Unit Safety Channel

4. Area Radiation Monitoring System

$\begin{array}{crr} & \$ & 4,000 \\ & 8,200 \\ & & 17,000 \\ & & 25,000 \\ & 54,200\end{array}$

II. Instrumentation/Equipment to Improve/Expand UFTR Capability

1. Replacement HPGe Detector and Components

$\$ \quad 12,685$

2. Special Low Energy HPGe Detector 13,000

3. NaI Gamma Spectroscopy System and Microcomputer 27,445

TOTAL \$ 107,530

Cost Sharing Proposed(12.83\%)

Requested Support

$\$ \quad \frac{13.800}{93.730}$


Table 2

FINANCIAL RESULTS OF UFTR 1990-1991 UNIVERSITY REACTOR INSTRUMENTATION GRANT

\begin{tabular}{||l|c|c|c|c||}
\hline $\begin{array}{c}\text { Instrumentation } \\
\text { Item }\end{array}$ & Proposal & $\begin{array}{c}\text { Actual } \\
\text { Cost }\end{array}$ & $\begin{array}{c}\text { Charges to } \\
\text { Grant }\end{array}$ & $\begin{array}{c}\text { Cost } \\
\text { Sharing }\end{array}$ \\
\hline $\begin{array}{l}\text { Air Particulate } \\
\text { Detector System }\end{array}$ & $\$ 4,000$ & $\$ 4,556.59$ & $\$ 3,971.98$ & $\$ 584.61$ \\
\hline Two-Pen Recorder & $\$ 8,200$ & $\$ 2,696.15$ & $\$ 2,350.23$ & $\$ 345.92$ \\
\hline $\begin{array}{l}\text { Single Unit Safety } \\
\text { Chänel }\end{array}$ & $\$ 17,000$ & $\$ 18,389.50$ & $\$ 16,030.13$ & $\$ 2,359.37$ \\
\hline Total & $\$ 29,200$ & $\$ 25,642.24$ & $\$ \mathbf{2 2 , 3 5 2 . 3 4}$ & $\mathbf{\$ 3 , 2 9 0 . 9 0}$ \\
\hline
\end{tabular}

Unused Portion of $\$ 25,700=\$ 3,347.66$ 
Table 3

\section{TOTAL COST FOR PROPOSED UFTR FACILITY INSTRUMENTATION AND EQUIPMENT UPGRADE FOR 1991-1992 GRANT YEAR}

I. Instrumentation/Equipment to Improve UFTR Operations

1. Dual Channel High Speed Chart Recorder for

Control Blade Drop Timing

2. Portable Neutron Sensitive Monitor

3. Area Radiation Monitor system (4 Channels)

4. Electronic Maintenance Tool Kit Package

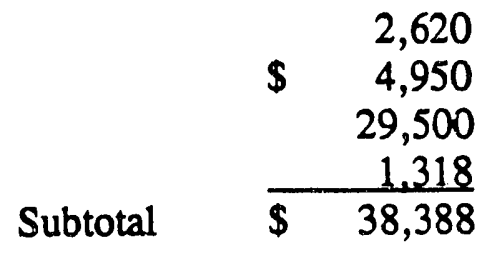

IIA. Equipment for Improvem nt of Existing Facility/NAA

Laboratory Operations

1. External Multichannel Buffer

$\$ \quad 4,235$

2. Spectrum Master

3. Low-Background Lead Shield with Cd-Cu Liner

Subtotal

6.700

$\$ 17,230$

IIB. Instrumentation/Equipment to Expand Facility Capability

1. Replacement HPGe Detector and Components

2. Special low Energy HPGe Detector

3. NaI Gamma Spectroscopy System with Microcomputer 13,200 27,445

Subtotal

$\$ 53,330$

TOTAL \$ 108,948

Cost Sharing Proposed (15.51\%) 16.900 
Table 4

FINANCIAL RESULTS OF UFTR 1991-1992 UNIVERSITY REACTOR INSTRUMENTATION GRANT

\begin{tabular}{||l|l|l|l|l|l||}
\hline & Proposal & Actual Cost & \multicolumn{1}{|c|}{ Status } & $\begin{array}{c}\text { Charges to } \\
\text { Grant }\end{array}$ & $\begin{array}{c}\text { Cost } \\
\text { Sharing }\end{array}$ \\
\hline $\begin{array}{l}\text { High Speed Chart Recorder } \\
\text { With Paper and Ink Supply }\end{array}$ & $\$ 2,620$ & $\$ 2,458.57$ & Received and in use & $\$ 2,077.52$ & $\$ 381.05$ \\
\hline $\begin{array}{l}\text { Portable Neutron Sensitive } \\
\text { Monitor }\end{array}$ & $\$ 4,950$ & $\$ 2,557.16$ & Received and in use & $\$ 2,160.83$ & $\$ 396.33$ \\
\hline $\begin{array}{l}\text { Electronic Maintenance Tool } \\
\text { Kit Package }\end{array}$ & $\$ 1,318$ & $\$ 2,494.88$ & Received and in use & $\$ 2,108.20$ & $\$ 386.68$ \\
\hline $\begin{array}{l}\text { External Multichannel } \\
\text { Buffer With Dual Port } \\
\text { Memory Cable }\end{array}$ & $\$ 4,235$ & $\$ 5,185.00$ & Received and in use & $\$ 4,677.14$ & $\$ 857.86$ \\
\hline $\begin{array}{l}\text { Spectrum Master With } \\
\text { Interface Cable }\end{array}$ & $\$ 6,295$ & $\$ 6,595.00$ & Roceived and in use & $\$ 5,796.78$ & $\$ 1,063.22$ \\
\hline $\begin{array}{l}\text { Low Background Lead Shield } \\
\text { Total }\end{array}$ & $\$ 6,700$ & $\$ 6,700.00$ & Received and in use & $\$ 5,662.57 *$ & $\$ 1,038.43 *$ \\
+412.04 \\
\hline \multicolumn{1}{|c|}{}
\end{tabular}

* Note that all of this year's grant is being used and it is hoped that the slight overage of $\$ 487.61$ can be covered by the funds left from the previous 1990-1991 grant year since the cost sharing on the sixth item(low background lead shield) has been increased by $\$ 412.04$ to avoid grant overcharges. 

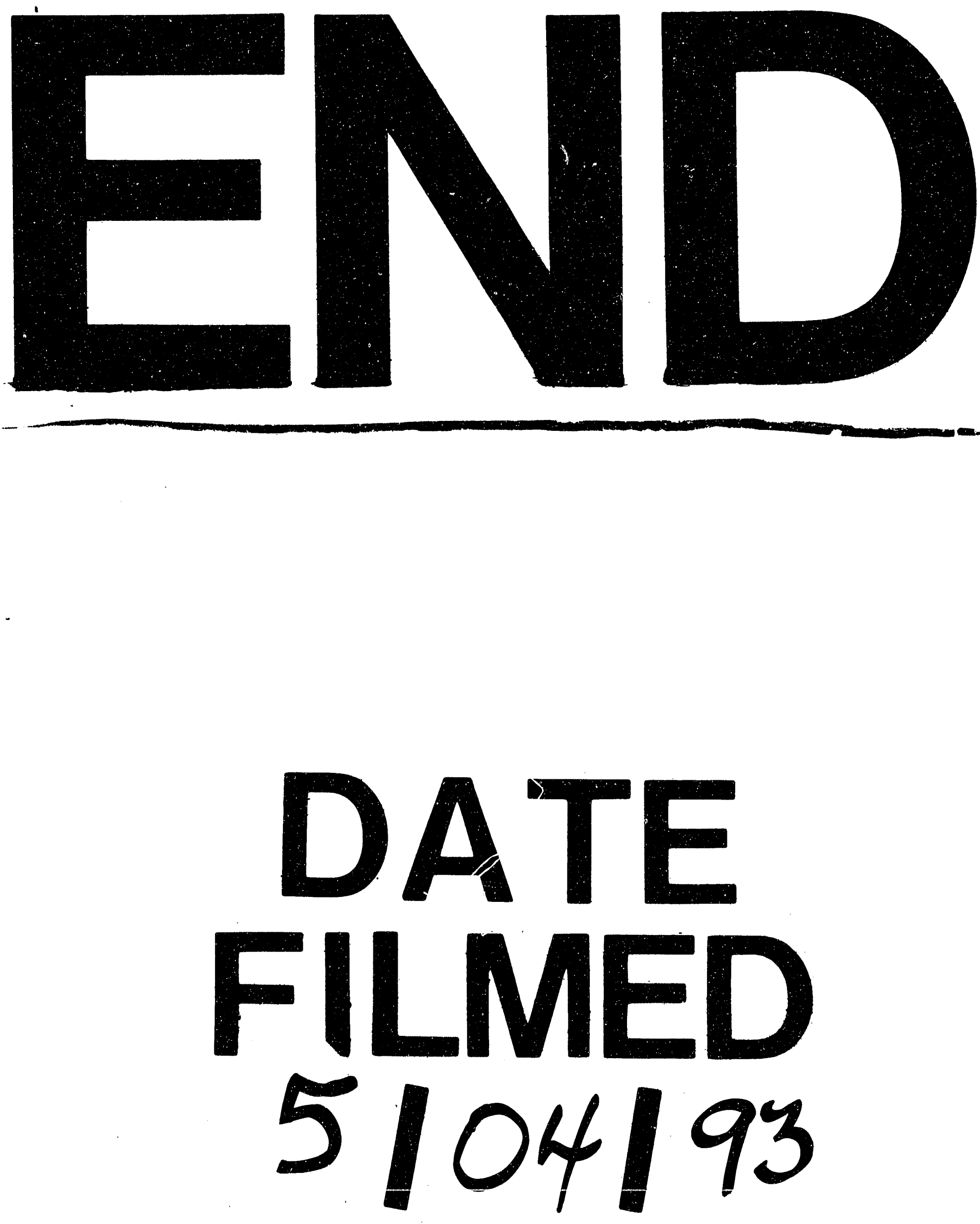

93

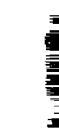


